\title{
O Saber e a Verdade na Psicanálise e na Universidade
}

Knowledge And Truth In Psychoanalysis And In The University

El Saber Y La Verdad En El Psicoanálisis Y En La Universidad

Leonardo J. B.

Danziato

Universidade de Fortaleza
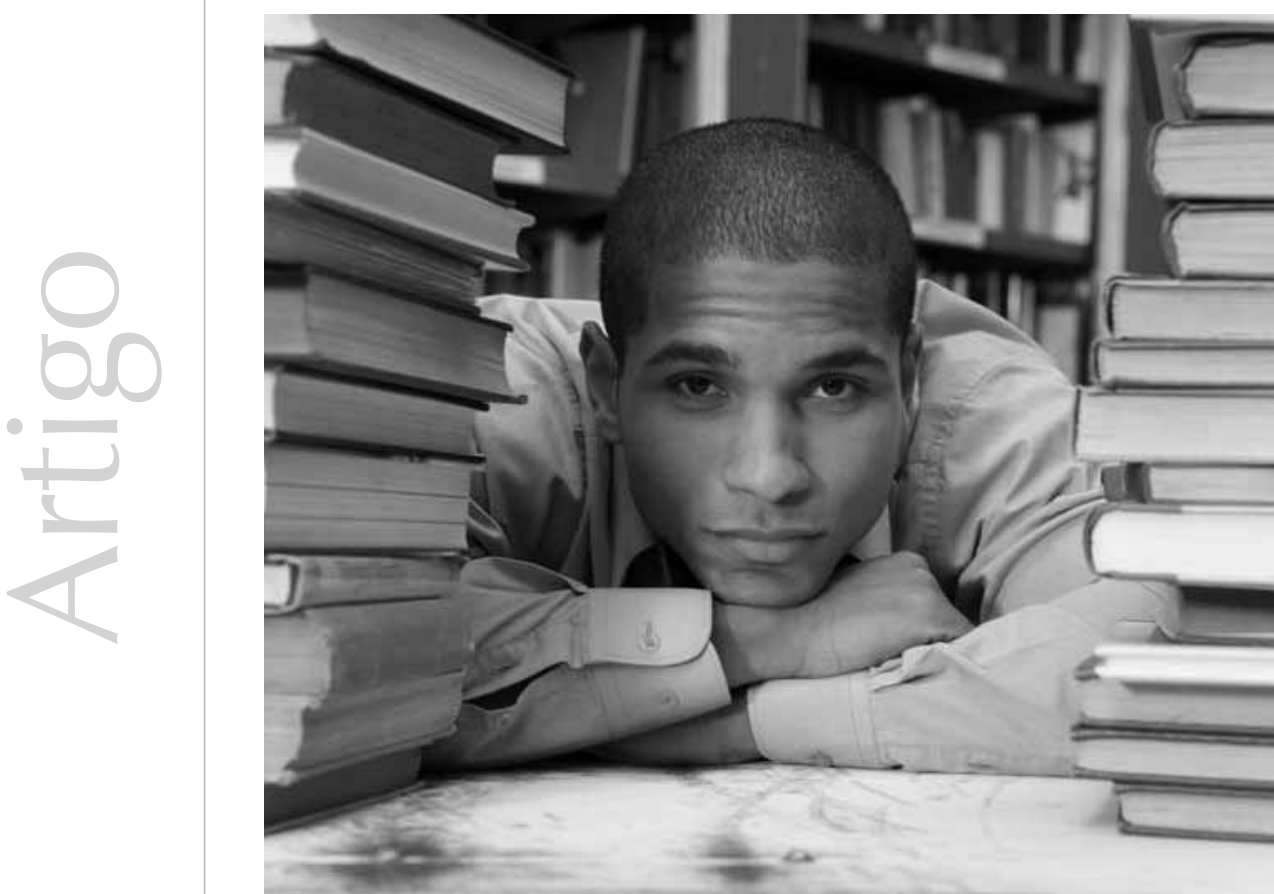
Resumo: $\mathrm{O}$ autor realiza uma discussão acerca da posição da psicanálise no âmbito da Universidade e em sua relação com a ciência. Para tanto, promove uma problematização sobre as relações históricas entre o saber e a verdade na estrutura desses discursos, apresentando uma argumentação que considera a função política do saber e da verdade na constituição do sujeito na modernidade. Para demonstrar a relação política e econômica entre ciência e capitalismo, de forma a fundamentar suas análises das apropriações que essas práticas e discursos realizam dessas categorias, articula proposições das obras de Lacan e Foucault, entendendo que essas análises históricas e genealógicas são necessárias para aprofundar o debate sobre as relações entre psicanálise, ciência e Universidade.

Palavras-chave: Psicanálise. Universidades. Verdade. Conhecimento. Gozo (Psicanálise).

Abstract: The author presents a discussion about the position of psychoanalysis within the university and its relationship to science. For that he promotes a questioning about the historical links between knowledge and truth in the structure of these speeches, presenting an argument that considers the political role of knowledge and truth in the constitution of the subject in modernity. To demonstrate the economic and political relationship between science and capitalism, in order to substantiate his analysis of the appropriations that these practices and discourses carry on these categories, he articulates propositions from the works of Lacan and Foucault, considering that these historical and genealogical analysis are necessary to deepen the debate on the relationship between psychoanalysis, science and academia.

Keywords: Psychoanalysis. Colleges. Knowledge. Truth. Fruition (Psychoanalysis).

Resumen: El autor realiza una discusión acerca de la posición del psicoanálisis en el ámbito de la Universidad y en su relación con la ciencia. Para eso, promueve una problematización sobre las relaciones históricas entre el saber y la verdad en la estructura de esos discursos, presentando una argumentación que considera la función política del saber y de la verdad en la constitución del sujeto en la modernidad. Para demostrar la relación política y económica entre ciencia y capitalismo, de forma de fundamentar sus análisis de las apropiaciones que esas prácticas y discursos realizan de esas categorías, articula proposiciones de las obras de Lacan y Foucault, entendiendo que esos análisis históricos y genealógicos son necesarios para profundizar el debate sobre las relaciones entre psicoanálisis, ciencia y Universidad.

Palabras clave: Psicoanálisis. Universidad. Conocimiento. Verdad. Gozo (Psicoanálisis).

As relações entre psicanálise e Universidade comportam uma complexidade histórica, discursiva, política e institucional, que exigem uma discussão que não se restrinja às proposições internas de cada campo. O que a Universidade requer da psicanálise, a partir de suas mais variadas formações - não só na Psicologia, na Sociologia, na Antropologia e na literatura, consideradas ciência humanas, ciências afins, portanto, mas também no campo das ciências da saúde - implica uma instalação do discurso psicanalítico fora de seus modelos práticos e discursivos habituais. Esse fenômeno impõe uma acomodação também discursiva e institucional, que rendeu muita polêmica, recusa e uma luta simbólica que até hoje parece não ter sido suficientemente elaborada. Não consideramos que recusar o lugar que a psicanálise ocupa hoje nos meios acadêmicos seja uma via lúcida para iniciar e desenvolver esse debate, mesmo que não devamos abrir mão do singular da psicanálise no que tange a sua prática e a sua formação. Procuraremos dirigi-lo por um caminho que desvele alguns movimentos históricos e discursivos que acreditamos fundamentar e esclarecer partes dessa polêmica.

Psicanálise e Universidade são termos cuja origem deve remontar aos discursos e práticas modernos. Mesmo que a Universidade como instituição date da idade média, a forma atual do ensino universitário foi gestada nesse ambiente que denominamos modernidade.

A psicanálise, por seu turno, só pode emergir em uma cultura moderna, em que o sujeito sofre os efeitos da destituição do poder soberano (Foucault, 1977) e do pátrio poder, assim como de uma nova relação entre a verdade e o saber, de maneira que essa verdade se instala em uma relação com a fala e com o sexo, tal como nos 
informa Foucault (1988). Essas condições de possibilidade da psicanálise não são desconhecidas nem por autores de fora do campo psicanalítico - como Foucault - nem tampouco por autores internos, como Lacan; obviamente, esses autores não discorrem da mesma forma sobre tais assuntos, mas há uma proximidade possível e importante em algumas considerações.

\section{A função política do saber na modernidade}

Esses dois autores, cada um a sua maneira e com objetivos diferentes, tentaram demonstrar que a modernidade operou mudança na relação discursiva entre o lugar do saber e da verdade, o que determinou a emergência das mais variadas práticas e saberes.

Foucault $(1977,1988)$ comprovou historicamente a intensificação da produção desses saberes, que respondiam às demandas políticas de ordenação, de adaptação e de subjetivação, sustentados por uma lógica do poder disciplinar, por uma anátomo-política e uma biopolítica que marcaram a condição genealógica da modernidade. Ele esclarece como se produziu uma nova "economia política da verdade", através de uma série de sistemas e de aparelhos de saber, que têm por função constituir e controlar o sujeito em sua condição de objeto, assim como em sua subjetivação. Nesse mesmo sentido, analisa todo um processo ético-político de subjetivação pela sexualidade, através da produção incessante de uma scientia sexualis (Foucault, 1988), ou seja, de uma intensificação dos saberes sobre o sexo.

Lacan, por sua vez, tentando entender certa posição da psicanálise diante da ciência e da modernidade, sugere que, nesse momento histórico, constitui-se um "mercado do saber" (Lacan, 1968-69/2004), fruto de mutação operada por uma cumplicidade política e discursiva entre Filosofia, ciência e capitalismo. A verdade teria feito junção com o saber, o que fundou um mercado do saber e da verdade. A partir daí, o saber passa a ser também um produto a ser ofertado, como lenitivo para a divisão subjetiva (Freud, 1972c) do sujeito, em suas catedrais universitárias, além de participar na produção dos objetos no mercado do gozo capitalista.

A modernidade, portanto, instaurou outra relação entre o saber e a verdade, instalando-a - a verdade - no âmbito de uma formalização matemática e lógica do real. Se a verdade era garantida para Descartes em um grande outro deificado - a substância divina cartesiana foi apenas para logo deslocá-la daí para a atividade analítico-sintética e transcendental do sujeito kantiano. A verdade passa a ser ou um saber que se retira do real - como no realismo filosófico - ou o produto da uma atividade analítico-sintética do sujeito - como no transcendentalismo kantiano.

Para Lacan, uma cumplicidade política e discursiva entre Filosofia, ciência e capitalismo produziu, na modernidade, uma relação de totalidade entre o saber e a verdade. O cogito cartesiano teria sido o momento inaugural desse atrelamento moderno entre o saber e a verdade, momento de reforçamento do sujeito da ciência, que ele define por um "ancoramento no ser" (1998a, p. 870) - uma atadura do ser. O que Descartes inaugura, abrindo as portas da modernidade, é uma relação de totalidade entre o saber e a verdade. Através do método, ele teria incluído a verdade toda no campo do saber. A partir daí, passa a ser possível produzir verdades, e não mais apreciá-las como um saber divino, tal como funcionava em uma relação ritual (Foucault, 1979, p. 116) com a verdade na Idade Média.

A relação entre verdade e saber, portanto, se modifica. Antes dessa operação discursiva, a 
1 É importante

lembrar que

Foucault, apesar de não ter produzido uma obra sobre a história da verdade - o que foi uma pena para todos nós - sempre se referiu aos deslocamentos políticos da verdade, e sua transformação de uma verdade-ritual para uma verdadeprova (Foucault, 1979).

2 Termo utilizado por Lacan para designar o mecanismo da psicose, mas também para dizer da relação da ciência com a divisão estrutural do sujeito (Lacan, 1998). verdade, por mais que habitasse um lugar totalizante - a substância divina - ainda assim se apresentava como desconhecida, ou como um saber divino que se manifestava na forma de um ritual ${ }^{1}$, muitas vezes mágico, da vontade de Deus. Daí por diante, inserida em uma ambiência epistemológica, a verdade pode ser sempre e toda conhecida e produzida; para tanto, basta que se utilize um bom método. Assim procedendo, não há dúvida de que se pode chegar a verdades claras e distintas (Descartes, 1986).

Foi Descartes, portanto, quem instituiu o sujeito suposto saber, ou seja, um lugar transferencial onde o saber pode ser totalizado, um Outro onde se situa a garantia do tudo-saber. O deus de Descartes ocupa esse lugar, já que seria a garantia das verdades eternas (Lacan, 1988; Porge, 1998).

Esses movimentos não se restringem a uma problemática meramente filosófica que se elabora, mas impõe-se como uma disposição discursiva que se inaugura na modernidade, isso porque essa nova localização discursiva do sujeito, da verdade e do saber produz suas consequências:

o real passa a ser considerado em termos matemáticos e lógicos;

a lógica matemática só é possível pelas capacidades transcendentais do sujeito moderno cartesiano-kanteano-hegeliano;

a modernidade, portanto, produz um sujeito que produz um saber e uma verdade;

assim, o saber e a verdade passam a se localizar nesse poder de síntese do sujeito;

sendo o sujeito que produz um saber, isso institui um "mercado do saber" (Lacan, 1968-69/2004), desenvolvido especialmente pela cumplicidade entre ciência e capitalismo e determinante no estabelecimento das Universidades.
Em uma visada psicanalítica, e especialmente para Lacan (1967-68), essa operação implicaria uma recusa originária, por parte de Descartes, daquilo que caracteriza o sujeito freudiano: a clivagem do sujeito. Essa recusa - movida pela angústia diante da dúvida - marcaria de uma vez por todas a relação discursiva da ciência com o saber e a verdade, implicando assim a recusa de uma verdade própria da dúvida, verdade essa que viria a se configurar como a verdade psicanalítica de uma divisão estrutural do sujeito, de uma falha inaugural. É essa recusa, essa foraclusão da verdade da divisão do sujeito que vai marcar de uma vez por todas as discussões e os desentendimentos entre psicanálise, ciência e Universidade.

Essa operação termina por fazer uma sutura da clivagem do sujeito aberta pela dúvida. A verdade, que se apresentava na própria enunciação (Lacan, 1998a) da dúvida - e, portanto, na spaltung do sujeito - fica assim desconhecida. O saber, assim considerado, passa a ser o operador de um fechamento subjetivo diante da dúvida, na forma de uma "foraclusão"2 da divisão subjetiva do sujeito. Para Lacan, é isso que permite a emergência da ciência como saber que foraclui a divisão do sujeito, daí porque afirma ser a ciência uma "paranóia bem sucedida" (Lacan, 1998, p. 889). É em oposição a essa atadura, mas a partir dela, que Lacan situa o sujeito freudiano.

\section{Ciência, capitalismo e mercado do saber}

Essa junção do saber com a verdade, efeito da cumplicidade entre ciência e capitalismo, teria possibilitado, então, o surgimento da ciência e de seu mercado, que se estabelece como um mercado do gozo, com a produção dos objetos-mercadorias, mas também como um mercado do saber (Lacan, 2004), com as suas instituições universitárias. É nessa condição de objeto de um mercado que podemos entender a economia dos saberes 
na contemporaneidade e o seu lugar de produção nas Universidades. Assim situado, o saber passa a ser também um produto a ser ofertado, como lenitivo para a divisão subjetiva do sujeito, em suas catedrais universitárias, além de participar na produção dos objetos no mercado do gozo capitalista. Fala-se muito da oferta de objetos no campo de subjetivação contemporâneo que se tornou o mercado, mas devemos também considerar a oferta de saberes como lenitivos e processos de subjetivação bastante intensos.

A Universidade e esses saberes modernos, portanto, não são simplesmente o produto de uma evolução científica interna de algumas disciplinas. Foucault (1999, 1999b, 2003) já demonstrou, em sua arqueogenealogia, as relações de poder intrínsecas a todo saber. Uma genealogia dos discursos esclarece que o poder dos discursos não depende fundamentalmente de sua precisão e objetividade, mas da assunção de um lugar de poder de enunciação da verdade. Se a "verdade é política" (Foucault, 1979a), é porque ela se deve ser considerada dentro dessas relações genealógicas de poder.

Assim, ao instituir um mercado do saber, a modernidade delimita um lugar político da verdade, e encena relações muito precisas de poder, que demarcam a instauração de um novo mestre - o mestre moderno (Lacan, 1992) - assim como um espaço institucional e discursivo responsável pela sua sustentação e produção: a Universidade e a ciência.

No desenvolvimento histórico desse processo de atadura entre o saber e a verdade, Lacan (1968-69/2004, 1992) esclarece que aquela recusa cartesiana diante da clivagem do sujeito teria sido, enfim, deslocada por Hegel para uma consistência do saber, fundando assim o saber absoluto. Se a primeira figura do sujeito suposto saber é o deus de Descartes, a segunda certamente é o saber absoluto de Hegel. Este último se fundaria em uma circularidade que se fecha em si mesma, descrita por Hegel em seu método dialético. Esse movimento equivaleria a uma topologia circular e fechada da esfera, própria da ideia de um saber como totalidade (Lacan, 196869/2004, p. 24).

O saber moderno, portanto, se institui como o lugar da verdade recusando toda "verdade para fora da dialética do sujeito e do saber" (Porge, 1998, p.117). O real fica, assim, escamoteado; delira-se com a possibilidade do sujeito tudo-saber, e não há buraco que não possa ser tamponado. É assim que se apresentam as intervenções da ciência contemporânea no real do corpo, tamponando imaginariamente os orifícios pulsionais.

Isso tem, inevitavelmente, repercussões políticas, já que esse novo saber, esse tudosaber (Lacan, 2004, p. 29) estabelece o que Lacan denomina uma "nova tirania do saber" (2004, p. 30), instituindo-o como o operador político da verdade na modernidade. A partir dessa injunção entre o saber e a verdade, a modernidade buscou incessantemente e sintomaticamente uma grafia plena do real, da qual a obra de Bentham é paradigmática, mas também os movimentos político-discursivos, como o nazismo e o comunismo.

Esse seria o sintoma da modernidade, pois, na ânsia totalitária e utilitarista de ordenação e de disciplinamento, ela termina por produzir aquilo que busca excluir: o resto. Com já afirmava Freud (1921/1976), o valor social da igualdade tem como efeito colateral a segregação do diferente.

O que se estabelece aqui é uma outra relação entre o saber, a verdade e o real, na forma de uma absolutização do mercado do saber (Lacan, 2004). O que se produz neste momento é uma ilusão ideológica, cientificista, de apreensão e de ordenamento de todo o real pelo simbólico, da constituição 
de uma "nova tirania do saber" (Lacan, 2004). O saber - científico ou não - onipotente passou a tentar reger todo o real; acreditouse piamente que tal saber poderia suturar, obturar todos os buracos da humanidade, curar todas as suas mazelas; bastava que fosse aplicado ao real.

O projeto político moderno é todo ele determinado por essa relação totalizante entre o saber e a verdade. A partir daí é que podemos entender melhor a constituição genealógica dessa ânsia de ordenamento e de disciplinamento do mundo, que se manifesta como uma paranóia disciplinar - uma "paranóia bem sucedida", como a nomeia Lacan (1998, p. 889) - dirigida ao corpo e ao espaço social, assim como uma obsessão quanto à assepsia do corpo e dos costumes - tal como descreveu Elias (1994).

\section{A ciência e a Universidade na relação com o real}

A relação que ciência e Universidade mantêm com o real se estabelece a partir dessa forma do saber-agente (S2), de um tudo-saber, que se apresenta como a crença de que se pode saber toda-a-verdade e assim, formar sujeitos - topologia própria do discurso universitário, tal como formulado por Lacan (1992). Essa relação topológica só poderia determinar vários contratempos e desentendimentos nas relações entre psicanálise, ciência e Universidade, isso porque, como nos lembra Lacan (2004), o saber da psicanálise é o saber de uma falha, um saber impossível, um saber do seu objeto - o objeto pequeno a - que implica uma impossibilidade do campo do real. Não há saber do objeto a que possa suturar a cisão do sujeito, daí porque o saber inconsciente não permite uma ontologia, pelo contrário, apresenta a hiância, a fenda por onde se pode, em psicanálise, definir o sujeito em sua evanescência. Trata-se, portanto, de um saber do real (Lacan, 2002) como o saber de uma impossibilidade.
É essa verdade, a verdade de um limite real do saber, ou melhor, de um limite real do simbólico que Descartes recusa, demarcando todo um campo onde essa falha passa a ser perseguida com o objetivo de suturá-la. O saber passa ser o operador moderno da relação do sujeito com o real: nada de divisão! Nada de angústia! Continua a saber! Eis o imperativo do mestre moderno que anima a relação da ciência com o saber e a verdade (Lacan, 1992).

Para a psicanálise, a relação constitutiva do sujeito com o Outro é marcada por uma dialética do desejo onde se encena uma perda originária - Urverdrängnung (Freud, 1915/1974) - de maneira que o desejo do Outro se apresenta como um enigma, como uma falta de saber que induz o sujeito a produzir uma demanda de saber (Lacan, 1998b), ou seja, ela funda um sujeito marcado pela relação constitutiva com o Outro, mas ancorado não em uma garantia de um saber absoluto, mas, pelo contrário, na falta, na divisão - spaltung - que implica a relação do sujeito com o desejo do Outro. Nesse sentido, ao contrário de como se apresenta em Descartes, o saber do Outro não garante uma sutura da clivagem do sujeito, já que não sabe toda a verdade. O sujeito aí não se apresenta como uma substância, mas em sua evanescência, em sua pulsação inconsciente: "falta ao Outro o significante que representa o sujeito de forma absoluta, é um fato de estrutura, e que define o desejo do Outro" (Baas \& Zaloszyc, 1996, p. 2).

Essa perda originária define o saber para a psicanálise como a causa e o efeito de uma perda entrópica. Ele se constitui a partir de uma impotência diante da verdade, mesmo que desencadeie uma busca em recuperar esse resto a que não conseguiu dar significado. Lacan já havia sugerido que o saber produz uma entropia (Lacan, 1992, p. 46), no sentido que ele não alcança todo o sentido da verdade (p. 48). A verdade, definida por ele 
3 Encontramos essas relações entre 0 sujeito, o saber, a verdade e o gozo na disposição topológica sugerida por Lacan para os discursos radicais (Lacan, 1992): um lugar do agente do discurso, que dependendo de qual significante ocupe esse lugar determina sua

"dominância" ; um lugar da verdade (sob a barra) que sustenta o lugar do agente; um lugar do outro, como o campo do saber e da linguagem e uma produção, como resto de toda operação significante. agente $\rightarrow$ outro (saber) verdade produção (mais-de-gozar) como "não-toda" (Lacan, 1985), mantém um traço do real, o que determina que não pode ser toda dita, não pode ser toda transcrita para o campo do simbólico; sempre deixa um resto: o objeto pequeno a. A verdade delata uma impotência (Lacan, 1992, p. 49) própria do saber. Assim, a onipotência reativa e reacionária dos saberes modernos ilustrados pelos projetos políticos modernos, pelos discursos científicos e pelos discursos universitários (no sentido que Lacan dá ao discurso universitário) - busca recobrir imaginariamente uma impotência estrutural.

\section{Universidade, ciência e a não relação sexual}

Essa foraclusão do sujeito e essa relação de totalização entre o saber e a verdade sustentam também outra ética, de forma que, sustentados pela topologia do discurso universitário (Lacan, 1992), observamos a produção de saberes-teorias que nada querem saber do sexual, ou melhor, da "nãorelação sexual” (Lacan, 1985, 2003).

Amparados por uma concepção do sujeito cognitivo, lançam-se em uma empreitada inglória para desconhecer ou governar o real do corpo, do sexo e da morte. O cognitivismo é a mais recente ideologia que anima a ideia capitalista e estática de um sujeito sem desejo e sem gozo, e que, por isso mesmo, poderia ser reprogramado para melhor desempenho; trata-se de uma nova Weltanschauug (Freud, 1933/1976a) de uma visão de homem contemporânea que o situa analogamente a um computador.

Para a psicanálise, a relação do sujeito com o saber implica o desejo e o gozo, pois atravessa seu corpo na encarnação da letra no real do corpo fazendo bordas em seus orifícios pulsionais. Não se trata de uma capacidade cognitiva, senão de uma "linguisteria", ou uma "alíngua" (Lacan, 1985, 2003), como sugere Lacan, que não pode ser considerada sem sua função de grafia do real do gozo e do corpo, portanto, não é possível falar ou pensar sem considerar o desejo e o gozo. É por isso mesmo que o "pensamento é gozo" (Lacan, 1985). Obviamente, isso subverte toda a nossa tradição cartesiana e também universitária relativa ao saber e ao pensamento.

Essa é a grande intrusão da psicanálise na cena filosófica e política contemporânea: Lacan invade o problema filosófico secular da verdade com a dimensão do gozo. A psicanálise recoloca em questão variáveis que não foram consideradas pelo pensamento político e filosófico tradicional: uma lógica inconsciente e o gozo daí originado. Introduz, assim, a problemática do gozo na relação do sujeito com a estrutura de linguagem, com o pensamento e com a verdade, uma intrusão, portanto, do gozo na relação entre o saber e a verdade. Diz Lacan: “O inconsciente não é que o ser pense... o inconsciente é que o ser falando, goze e... não queira saber de mais nada disso" (Lacan 1985, p. 143)

A verdade, assim considerada, ultrapassa a lógica filosófica do pensamento; sempre se encontra em uma relação discursiva com o saber e com o gozo, ou seja, ela implica sempre uma impossibilidade, não só de tudo saber mas também de tudo gozar.

A relação discursiva que Lacan estabelece entre o saber, o gozo e a verdade diz respeito, portanto, aos limites e às bordas possíveis na relação impossível com o real: "O real não é antes de mais nada para ser sabido", diz Lacan (2003, p. 442), insinuando que não se trata de sabê-lo, mas de bordejá-lo. A verdade não passa de um lugar no discurso que delata a impotência em tudo-saber, ou de dizê-la toda; a verdade é "não-toda" (Lacan, 1985). Dependendo de como se trata essa incompletude, podemos caracterizar os discursos, pois existem aqueles que supõem tê-la encontrado, ou que propõem 
Esses exemplos comprovam a ironia de Lacan ao afirmar que "a verdade suporta tudo: a gente mija, tosse e cospe nela" (2003, p. 440). um projeto de encontro possível, mas há também os que sabem e trabalham com essa impossibilidade. Essa incompatibilidade, contudo, é produtiva, pois, como diz Lacan, muita coisa "se fabrica a partir do fato de saber e verdade serem incompatíveis" (2003, p. 441).

\section{Politizar o saber, a verdade e o gozo}

Há, como vimos, um movimento discursivo próprio do projeto político moderno que busca reinserir toda a verdade no campo do saber, almejando uma gestão e um controle plenos do real e do gozo. Isso fica claro nos projetos disciplinares e bio-políticos criados na modernidade, tais como os já citados acima: o alienismo, o higienismo, a medicalização das condutas e dos corpos, o comunismo, o nazismo, e, mais contemporaneamente, o "controle" (Deleuze, 1992), próprio das sociedades pós-modernas. Esses exemplos comprovam a ironia de Lacan ao afirmar que "a verdade suporta tudo: a gente mija, tosse e cospe nela" (2003, p. 440).

De acordo com a forma como cada discurso trata essa relação entre o saber, a verdade e o gozo, são constituídas uma ética e uma política peculiar. Os saberes, entretanto, podem movimentar-se dentro das mais variadas posições discursivas em um movimento pendular que não é excludente das outras posições; os giros discursivos não são excludentes.

O caráter político intrusivo da psicanálise - e por isso mesmo rechaçado - é acusar a sutura simbólica ou imaginária na qual os discursos podem incorrer no afã de grafar uma verdade, diante dessa impossibilidade marcada pelo real. Esse descompasso, esse desencontro fundamental entre o saber $e$ a verdade não evita o agenciamento e a capitalização da angústia que daí resulta; pelo contrário, isso funciona como causa desses movimentos discursivos. A verdade, em sua face de real, em sua impossibilidade estrutural, pode ser manipulada política e discursivamente, dependendo de onde esteja situada, de onde se localize o saber e o gozo que lhe concernem. Como indica Lacan, "é nessa articulação com o real que se encontra a incidência política em que o psicanalista teria lugar, se fosse capaz de fazêla" (2003, p. 443).

Como vimos, as ilusões e as ideologias religiosas e políticas, assim como a própria estrutura discursiva da cultura, retiram daí sua fonte. Mais do que isso, pode-se pensar que o laço social seja uma tentativa de, apesar da impossibilidade de encontro com o outro, ainda assim, fazer laço; por isso, é possível introduzir a dimensão do gozo em sua correlação com uma lógica e com uma topologia do laço social.

A psicanálise, em sua intrusão política, acusa o fracasso das totalizações, mesmo que isso signifique dar um tiro no próprio pé, já que acusa também o fracasso de sua própria suposição de cura. É nesse sentido que afirmamos que a psicanálise desvela a verdade da política. É ela própria o retorno de uma verdade política, um "sintoma da modernidade" (Lacan, 2004).

A intrusão à qual Lacan se refere é uma intrusão do gozo nos discursos, que sinaliza uma disjunção inevitável entre o saber e a verdade. Como já afirmamos, o gozo se apresenta como um intruso tanto no corpo como na política, porque, paradoxalmente, é o que faz girar os discursos, mas, ao mesmo tempo, é o que parece ser escamoteado por eles. Se não há discurso que não seja do gozo, é na condição de rechaço desse real, desse elemento intruso, que os discursos com ele lidam, na tentativa vã de grafar o todo do gozo ou de dissolver - no simbólico, ou no imaginário - o real de sua impossibilidade. 
É a partir dessas relações entre o saber, a verdade e o gozo que devemos entender a complexidades políticas e discursivas entre psicanálise e Universidade, pois, por um lado, parece-nos importantíssimo que se escute e se considere - mesmo com as incompatibilidades discursivas - os efeitos politizantes da introdução desses limites e dessa impossibilidade entre o saber e a verdade nas instituições universitárias. É preciso estar no meio universitário para anunciar politicamente que todo discurso gira em torno de uma impossibilidade, que paradoxalmente o anima, e que todo discurso que implique uma pretensão de totalidade, ou de universalização - como em uma Weltanschaüung - está fadado ao fracasso, mesmo que seja esse fracasso o que anima e causa uma busca incessante dos discursos em reinserir esse pedaço do real em sua linguagem.

Por outro lado, a psicanálise não pode prescindir de ocupar seu lugar nessa composição moderna dos discursos, sob pena de ser posta em uma condição de prática esotérica e artesanal. Por mais que seja crucial manter uma posição singular na clínica, seria uma ingenuidade discursiva perder seu lugar político na ordem dos discursos. Se os discursos não são excludentes, eles animam uma lógica político-discursiva inevitável na modernidade. Recusá-la seria fechar-se em um anacronismo romântico e politicamente inocente, o que não é nada analítico... 


\section{Leonardo J. B. Danziato}

Psicanalista com formação em Psicologia pela Universidade Federal do Ceará; Mestre e Doutor em Sociologia pela Universidade Federal do Ceará; Professor Titular da Graduação e do Programa de Pós-Graduação em Psicologia da Universidade de Fortaleza, Fortaleza - CE - Brasil.

E-mail: leonardodanziato@unifor.br

\section{Endereço para envio de correspondência:}

Rua Álvaro Correia, 455, AP 801 bloco Malta - Varjota, Fortaleza/CE. CEP: 60165-230

Recebido 12/02/2010, Aprovado 31/07/2012.

\section{Referências}

Baas, B., \& Zaloszyc, A. (1996). Descartes e os fundamentos da psicanálise. Rio de Janeiro: Revinter.

Deleuze, G. (1992). A sociedade de controle. In Conversações. Rio de Janeiro: Ed 34

Descartes, R. (1986). O discurso do método. Portugal: Publicações Europa-América.

Elias, N. (1994). O processo civilizador (Vol. 1). Rio de Janeiro: Jorge Zahar.

Foucault, M. (1977). Vigiar e punir. Petrópolis, RJ: Vozes.

Foucault, M. (1979). A casa dos loucos. In Microfísica do poder. Rio de Janeiro: Ed. Graal.

Foucault, M. (1979a). Nietzsche, a genealogia e a história. In Microfísica do poder. Rio de Janeiro: Ed. Graal.

Foucault, M. (1988). A história da sexualidade I - a vontade de saber. Rio de Janeiro: Graal.

Foucault, M. (1999). A ordem do discurso. São Paulo: Loyola.

Foucault, M. (1999a). A verdade e as formas jurídicas. Rio de Janeiro: Nau Ed.

Foucault, M. (2003). Estratégia poder-saber. In Ditos e escritos (Vol. IV). Rio de Janeiro: Forense Universitária.

Freud, S. (1972). A Interpretação dos Sonhos. In Edição Standard Brasileira das Obras Completas de Sigmund Freud (Vol. IV e V). Rio de Janeiro Imago (Trabalho original publicado em 1900).

Freud, S. (1974). Artigos de metapsicologia.In Edição Standard das Obras Completas de Sigmund Freud (Vol. XIV). Rio de Janeiro, Imago (Trabalho original publicado em 1915).

Freud, S. (1976). Psicologia dos grupos e análise do ego. In Edição Standard das Obras Completas de Sigmund Freud (Vol. XVIII).
Rio de Janeiro: Imago (Trabalho original publicado em 1921).

Freud, S. (1976a). Novas conferências introdutórias à psicanálise. Conferência XXXV - a questão de uma Weltanschaüung. In Edição Standard Brasileira das Obras Completas de Sigmund Freud (Vol. XXII). Rio de Janeiro: Imago (Trabalho original publicado em 1933).

Lacan, J. (1967-1968). O ato analítico. Livro XV. Notas de Curso. Mimeo.

Lacan, J. (1985). O seminário. Livro 20. Mais, ainda. Rio de Janeiro: Jorge Zahar.

Lacan, J. (1988). O Seminário, livro 11 - Os quatro conceitos fundamentais da psicanálise. Rio de Janeiro: Jorge Zahar.

Lacan, J. (1992). O seminário. Livro 17. O avesso da psicanálise. Rio de Janeiro: Jorge Zahar.

Lacan, J. (1998). A ciência e a verdade. In Escritos. Rio de Janeiro: Jorge Zahar.

Lacan, J. (1998a). Subversão do sujeito e a dialética do desejo no inconsciente freudiano. In Escritos. Rio de Janeiro: Jorge Zahar.

Lacan, J. (2002). RSI. Versión crítica. (Seminário 22. Publicación para circulación interna de la Escuela Freudiana de Buenos Aires. Mimeografada. Seminário dos anos 1974-75).

Lacan, J. (2003). Radiofonia. In Outros escritos. Rio de Janeiro: Jorge Zahar.

Lacan, J. (2004). De um outro ao outro. Seminário 16. (Publicação interna do Centro de Estudos Freudianos do Recife CEF Recife, Seminário dos anos 1968-69).

Porge, E. (1998). Os nomes do pai em Jacques Lacan. Pontuações e problemáticas. Rio de Janeiro: Companhia de Freud. 